\title{
Performances of Heat Transfer and Fluid Flow in the Shell and Tube Heat Exchanger with Novel Sextant Fan Baffles
}

\author{
Mei Jin ${ }^{1, a}$, Jian Fang ${ }^{1}$, Li Zhan ${ }^{1}$ and Hong-jiao Liu ${ }^{1,2, b^{*}}$ \\ ${ }^{1}$ Hubei Key Laboratory of Industrial Fume \& Dust Pollution Control, Jianghan University, Wuhan \\ 430056, Hubei, China \\ ${ }^{2}$ School of Energy and Power Engineering, Huazhong University of Science and Technology, \\ Wuhan, 430056, Hubei, China \\ ameijin_hhun@126.com, ${ }^{\mathrm{b}} \mathrm{mxw1996@163.com,} \mathrm{*Corresponding} \mathrm{author.}$
}

Keywords: Shell and tube heat exchanger; numerical simulation; sextant fan baffle; segmental baffle.

Abstract: For the high shell side pressure drop of the traditional segmental baffled heat exchanger, a novel sextant fan baffled heat exchanger was put forward in this paper. The 3-dimensional physical model of the novel sextant fan baffled heat exchanger was built, CFD software was used to obtain detailed shell side fluid flow behavior and heat transfer performances, comparison was also made between the new and the traditional segmental baffled heat exchanger. Results show that the pressure drop of the new sextant fan baffled heat exchanger is about $72.3-74.6 \%$ greater than that of the traditional segmental baffled heat exchanger under the import velocity of shell side from 2 to 10 $\mathrm{m}^{3} / \mathrm{h}$. When the import velocity is low, the difference of heat transfer coefficient between the two heat exchangers is minor, and the comprehensive performance of the new sextant fan baffled heat exchanger is $33.14-65.25 \%$ greater than that of the heat exchanger with traditional segmental baffles under various import velocities.

\section{Introduction}

Shell and tube heat exchangers (STHXs) have been the most widely used equipment in the industrial fields ${ }^{[1,2]}$. In STHXs, supporting parts not only provide the supporting function for the tubes but also play a spoiler role for fluid flow, which is an important part in STHXs. According to the previous research ${ }^{[3-5]}$, aiming at the defects existing in the traditional heat exchanger with segmental baffles, the mechanisms of heat transfer enhancement and pressure drop reduction are analyzed of STHXs with the different structure baffle parts, such as circle orifice baffle, overlap helical baffles, helical baffle ${ }^{[6]}$, and so on. Based on the previous researches, a new sextant fan baffle is put forward in this paper. In addition, fluent numerical simulations can offer the only cost-effective means and a good repeatability for realistic process simulations ${ }^{[2-3]}$. 3-dimensional physical model of the sextant fan baffled heat exchanger was built, CFD software was used to obtain detailed shell side fluid flow and heat transfer performances. Furthermore, a comparison was also made between the new sextant fan baffled heat exchanger and the traditional segmental baffled heat exchanger.

\section{Numerical Calculation Model}

Physical model. The structural parameter of STHXs is listed in Table 1. The geometry model of the new sextant fan baffle is shown in Fig. 1 and the installation diagram of baffle parts in STHXs is illuminated in Fig. 2. The spacing of each baffle, the number of tube and the structural distribution is the same in the sextant fan baffled heat exchanger (SFBHX) with that in the traditional segmental baffled heat exchanger (SBHX).

Table 1 Structural parameters of STHXs

\begin{tabular}{ccccc}
\hline $\begin{array}{c}\text { Shell } \\
\text { diameter }\end{array}$ & $\begin{array}{c}\text { Shell } \\
\text { length }\end{array}$ & $\begin{array}{c}\text { Tube } \\
\text { number }\end{array}$ & $\begin{array}{c}\text { Arrangement } \\
\text { mode of tube }\end{array}$ & $\begin{array}{c}\text { Inlet diameter of } \\
\text { shell-side }\end{array}$ \\
\hline $209 \mathrm{~mm}$ & $1886 \mathrm{~mm}$ & 22 & Regular triangle & $50 \mathrm{~mm}$ \\
\hline
\end{tabular}




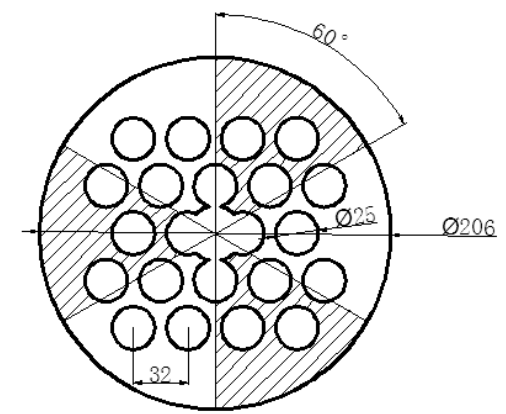

Fig. 1 Geometry model of sextant fan baffle

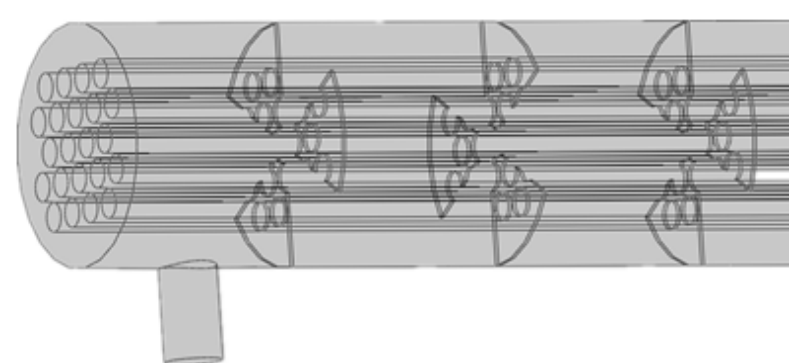

Fig.2 Installation diagram of sextant fan baffles in STHXs

Establishment of Model. During the numerical simulation with Fluent software package, it should assume the following: (1) the fluid should be incompressible Newton fluid; (2) no heat transfer was occurred in the horizontal direction; (3) the interval between the baffle plate and the tube, as well as the interval between the baffle plate and the shell should be neglected; (4) the structure of impingement plate, spacer and tie rod should be simplified; (5) the flow state and the heat transfer of the fluid should be in agreement with the continuity equation, energy equation and momentum equation ${ }^{[7]}$. According to a high quality and adaptive, Hyper Mesh meshing using unstructured tetrahedral mesh was adopted in this paper. The appropriate grid unit size was selected to guarantee the minimum grid orthogonal quality of 0.25 . RNG k- $\varepsilon$ turbulence model was adopted in the numerical simulation based on the preliminary work ${ }^{[8]}$. Segregated implicit was employed to guarantee the stability of the calculation convergence. Second order upwind method was adopted to deal with the momentum, turbulent kinetic energy and turbulent dissipation rate. The SIMPLE algorithm for Pressure-Linked and Velocity-Linked Equations was used to couple the continuity and Navier-Stokes equations. The wall function was introduced for considering the influence of the boundary layer on the turbulent flow of the fluid. Residuals were reduced to the order of $10^{-5}$ or less $^{[9]}$. Furthermore, during the numerical simulation, the import fluid condition under the specified temperature and the degree of turbulence were applied for the import fluid in STHXs, and the free boundary condition was adopted for the export fluid.

\section{Results and discussion}

Pressure nephogram of STHXs. The pressure nephogram of SBHX and SFBHX under the import velocity of $4 \mathrm{~m}^{3} / \mathrm{h}$ is shown in Fig. 3 and 4, respectively. From these Figures, it is clear that the flow dead zone in SBHX is larger than that of SFBHX, which means the pressure change in SBHX is higher along with the flow direction than that in SFBHX. In addition, for SFBHX, the pressure change is more uniform in the radius direction to result a lower flow resistance than that for SBHX.

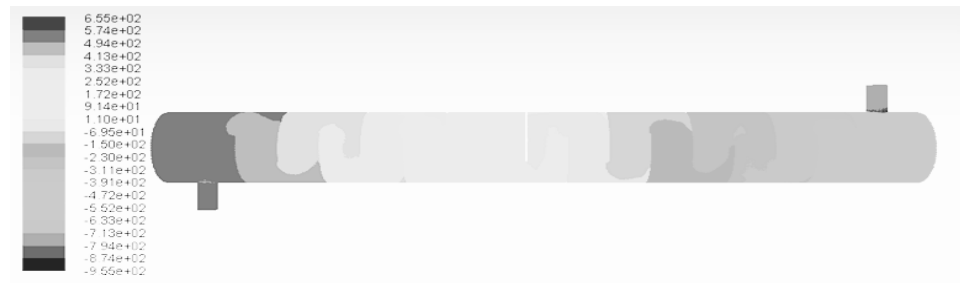

Fig. 3 Pressure nephogram of SBHX

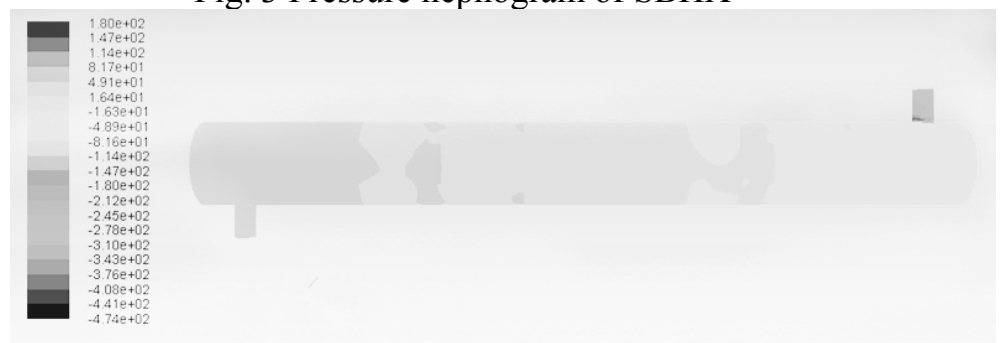

Fig. 4 Pressure nephogram of SFBHX 
Performance of the pressure drop. Fig. 5 show the performances of pressure drop in STHXs with the traditional segmental baffles and the sextant fan battles under the fluid velocity from 2 to $10 \mathrm{~m}^{3} / \mathrm{h}$. From Fig. 5, note that, the pressure drop increases with the increasing of the fluid velocity in both heat exchangers with the different increasing amplitudes. In Fig. 5, it can be found the pressure drop of SFBHX is about $72.3-74.6 \%$ higher than that of SBHX under various import velocities. As we all known, when the fluid flows through the supporting part in STHXs, the flow direction can be changed and the turbulence effect can be generated ${ }^{[4-6]}$. Then, there is a distribution difference in velocity profile and temperature profile of the fluid in different baffled heat exchanger. When the fluid flows through the different supporting parts in STHXs, the eddies of fluid are the asymmetric structure in SBHX, whereas the eddies of fluid are the symmetrical structure in SFBHX. Accordingly, there is a lower resistance to the fluid flow in SFBHX rather than that in SBHX, which can result a higher pressure drop in SBHX than that in SFBHX.
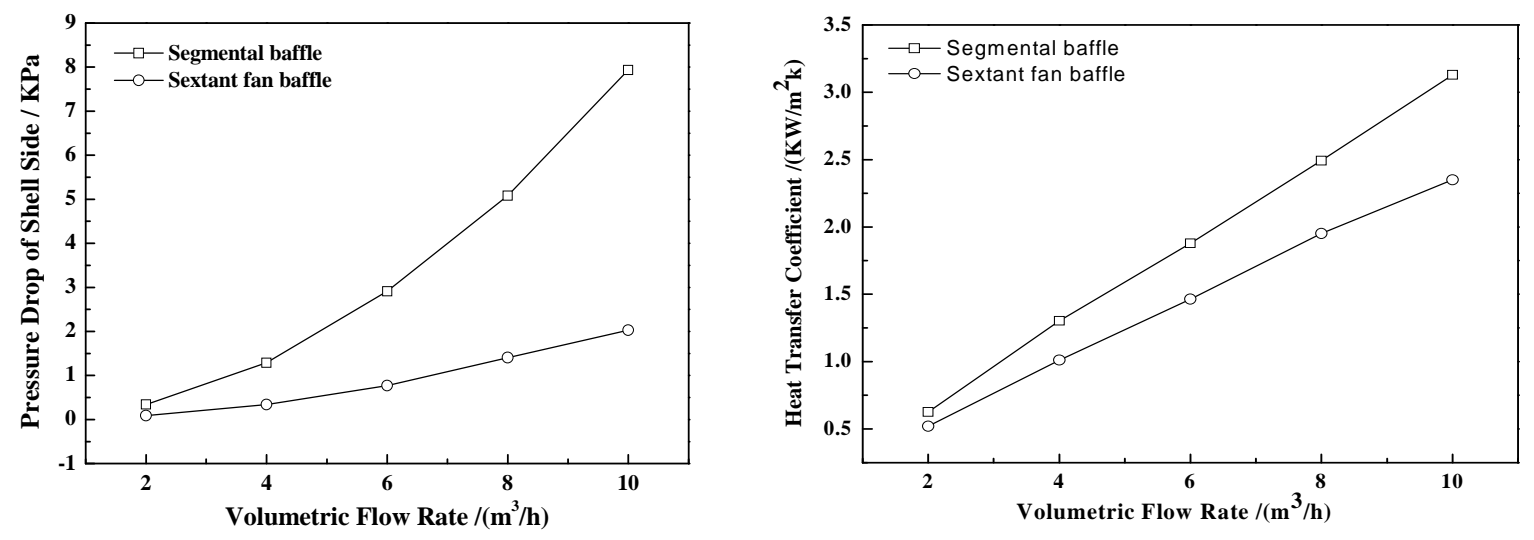

Fig.5 Pressure drop vs volumetric flow rate

Fig. 6 Heat transfer coefficient $v s$ volumetric flow rate

Performance of heat transfer coefficient. Fig. 6 indicate the relationships of the heat transfer coefficient to the volumetric flow rate in STHXs with the traditional segmental baffles and the sextant fan baffles. In Fig. 6, the heat transfer coefficients increase with the increasing of the volumetric flow rate in both heat exchangers. However, the heat transfer coefficient of SFBHX is smaller than that of SBHX under the same import velocity of shell side. Note that, the performance of the turbulent flow can be generated in STHXs with supporting baffles. Therefore, the temperature profile of the fluid varies from the traditional segmental baffles to the sextant fan baffles in STHXs. For the traditional segmental baffles, there is a larger disturbance of the fluid flow, which leads to a higher overall temperature distribution. As a result, the heat transfer coefficient of SBHX is higher than that of SFBHX. It is also found that the difference of the fluid disturbance is small between the traditional segmental baffle and the sextant fan baffle when the volumetric flow rate is lower. As consequence, when the import velocity is low, the difference of heat transfer coefficient between SFBHX and SBHX is minor.

Performance of the comprehensive heat transfer. J-F factor is selected to represent the performance of the comprehensive heat transfer of STHXs. The relationships between J-F factor and the volumetric flow rate in SBHX and SFBHX are shown in Fig. 7. It can be observed that J-F factor decreases slowly with the increasing of the flow velocity slowly in SFBHX, and J-F factor increases first and then decreases slowly with the increasing of the flow velocity in SBHX. The variation tendency is related to the characteristics of fluid flow and heat transfer in different baffled heat exchangers. Compared with SBHX, the heat transfer coefficient of SFHX is lower and the pressure drop is much higher. Taken together, these factors have led to a better comprehensive heat transfer performance in SFBHX. Then, in the range of the volumetric flow rate of $2-10 \mathrm{~m}^{3} / \mathrm{h}$, the comprehensive performance of SFBHX is $33.14-65.25 \%$ greater than that of SBHX under various import velocities. 


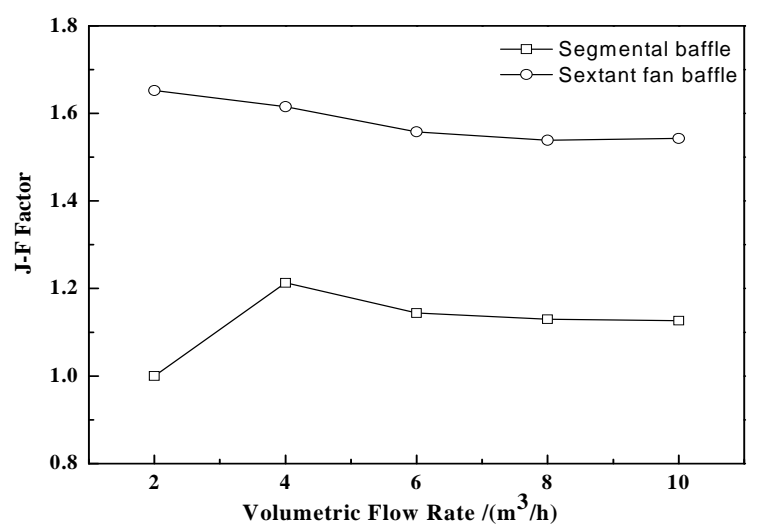

Fig. 7 J-F factor vs Volumetric flow rate

\section{Conclusion}

In this paper, the numerical simulations of STHXs were conducted to investigate the characteristic of fluid flow and heat transfer in SBHX and SFBHX. Furthermore, the performance of pressure drop, the heat transfer coefficient, and the comprehensive heat transfer was studied in detail. Combining with the pressure nephogram of STHXs, it is clear that there is a distribution difference in velocity profile and temperature profile of the fluid in two different baffled heat exchangers. Compared with SBHX, SFBHX can provide a more uniform distribution in both velocity and temperature profiles. As a result, the pressure drop of SFBHX is about $72.3-74.6 \%$ higher than that of SBHX under various import velocities of shell side. In addition, when the import velocity is low, the difference of heat transfer coefficient between SBHX and SFBHX is minor. Taken together, the comprehensive performance of SFBHX is about 33.14-65.25\% greater than that of SBHX.

\section{References}

[1] Y. D. Chen, X. D. Chen: Mach. Eng.(China), 10(2013), 134-143.

[2] L. H. Gu, X. Ling, H. Peng: Heat Mass Transfer., 48(2012), 1707-1721.

[3] E. Neshat, S. Hossainpour, F. Bahiraee: Heat Mass Transfer., 50(2014),877-885.

[4]W. J. Du, H. F. Wang, X. Cao, et al: CIESC Journal(China), 9(2013), 3123-3129.

[5] J. X. Wu, Q. W. Dong, M. S. Liu, et al: CIESC Journal(China), 2(2006), 213-216.

[6] Y. S. Wang, X. Y. Zhang, Z. C. Liu, et al: CIESC Journal(China), S1(2012), 99-104.

[7] L. Liu, T. M. Song, J. J. Guan, et al: Light Ind. Mach.(China), 30(2012), 18-21.

[8] M. Jin, L. Zhan, G. X. Yu, et al: Adv. Mater. Res. 1008-1009(2014), 910-913.

[9] F. N. Taher, S. Z. Movassag, K. Razmi, R. T. Azar: Appl. Therm. Eng.,44(2012), 143-149. 